\title{
Research on Method of Dynamic Stability Analysis for Slopes of Earth and Rockfill Dam Basing on the P-Z Model
}

\author{
Hongyang ZHANG, Shuai LI, Xianqi ZHANG, Liwei HAN, Zelin DING, Cundong XU
}

\begin{abstract}
According to the problems in dynamic stability analysis for slopes of earth and rockfill dam, the P-Z constitutive model, which is a kind of the multi-mechanism plastic model based on generalized plasticity, is introduced in the paper. Strength reduction factors of P-Z model are derived and verified, and based on them a new kind of method of dam slopes dynamic stability is put forward. For the method, the dynamic stability of dam slopes is judged by dynamic displacement time history and postearthquake permanent displacement. The results show that local instability of dam slopes and variation features of dynamic response are obtained by the method, which is more reasonable.
\end{abstract}

Keywords: dynamic stability analysis; local instability; P-Z constitutive model; strength reduction FEM

\section{INTRODUCTION}

Currently, the common analysis methods of dynamic stability for earth and rockfill dam slopes are the quasistatic method and the Newmark-slider method. Although these methods are simple and easy to calculate, there are many assumptions and the calculation results have a larger arbitrariness. The finite element method was used in static stability analysis of slope in the 1970s. It is a more rational analysis method, which considers the balance of forces and moments of the whole slope and the constructive relation of slope soil.

However, in recent years the finite element method has been applied to slope dynamic stability. Liu Hanlong et al. [1] proposed a method that used average safety factor to evaluate the stability of slope based on the relation curve of safety factor and time. Li Yushu et al. [2] drew the time history curve of dynamic safety factor on the most dangerous sliding surface with the same method, and used the average dynamic safety factor method and permanent deformation of earthquake to evaluate the earthquake dynamic stability of slope. Ma Fangfang [3] proposed two-time history analysis methods of dynamic stability about high earth and rockfill dam. Recently, there are many other researchers who have done a lot of useful researches [4-11]. These studies on the dynamic stability of slope are very significant attempts, but in the studies the dynamic safety factor is defined as the ratio of shear force and shear stress of a moment, when the unit is not necessarily in the limit equilibrium state, which is inconsistent with premise (limit equilibrium state) defined by conventional safety factor. Therefore, based on the static slope stability analysis and taking into consideration the selection of constitutive relationship of slope material, dynamic artificial boundary and instability criterion of finite element strength reduction, a new dynamic stability analysis method of slope is proposed.

\section{FINITE ELEMENT STRENGTH REDUCTION PARAMETERS OF P-Z MODEL}

The P-Z model [12-15] which is based on the generalized plastic mechanics theory was proposed by
Pastor and Zienkiewicz. The model can describe the static and dynamic characteristics of soil in the condition of cyclic loading or uniaxial loading, drainage or not. Besides, in deriving plastic deformation, it is not necessary to firstly define the yield surface and plastic potential surface, but to deduce the yield surface and the plastic potential surface through loading direction vector and loading and unloading direction vector of plastic potential. There are 12 parameters about P-Z constitutive model, which are $M_{g}, M_{f}, \alpha_{g}, \alpha_{f}, \beta_{0}, \beta_{1}, H_{0}, \gamma_{D M}, H_{u 0}, \gamma_{u}$, $K_{\text {evo }}$ and $K_{\text {eso, }}$ of which $\gamma_{D M}, H_{u 0}$ and $\gamma_{u}$ are related to dynamic analysis. The parameters can be determined by conventional three axis test or experience. The authors have recently studied the wetting deformation and dynamic characteristics of earth-rockfill Dam based on P$Z$ Model, and the reasonable results are obtained [16-17] (Intro parameters and test verification, see refs [18-19]).

\subsection{Selection of finite element strength reduction parameter of P-Z model}

Plastic potential surface equation of P-Z model:

$G=q-M_{g} p\left(1+\frac{1}{\alpha_{g}}\right)\left[1-\left(\frac{p}{p_{g}}\right)^{\alpha_{g}}\right]=0$

Yield surface equation of P-Z model:

$F=q-M_{f} p\left(1+\frac{1}{\alpha_{f}}\right)\left[1-\left(\frac{p}{p_{f}}\right)^{\alpha_{f}}\right]=0$

where $q$ is deviatoric stress; $p$ is spherical stress; $p_{g}$ and $p_{f}$ are the constants of spherical stress; $M_{g}$ is the slope of critical state line; the value of $M_{f}$ is related to $M_{g} ; \alpha_{g}$ and $\alpha_{f}$ are the material parameters which implicitly reflect the Poisson's ratio and are related to strain and stress state.

To the associated flow rule, there is

$$
\left\{\begin{array}{l}
\alpha_{f}=\alpha_{g}=m c+n \\
M_{f}=M_{g}=\frac{6 \sin \varphi}{3-\sin \varphi \sin 3 \theta}
\end{array}\right.
$$


And to the non-associated flow rule, there is

$$
\left\{\begin{array}{l}
\alpha_{f}=\alpha_{g}=m c+n \\
M_{f}=D_{r} M_{g}=D_{r} \frac{6 \sin \varphi}{3-\sin \varphi \sin 3 \theta}
\end{array}\right.
$$

where $D_{r}$ is the relative density of material; $c, \varphi$ are the soil cohesion and internal friction angle; $\theta$ is the Lode angle; $m, n$ are constants. The calculation of $\alpha_{g}$ and $\alpha_{f}$ is complex, and linear relationship with cohesion is assumed, and the values are generally 0.3 to 0.5 according to the experimental results.

\subsection{Case 1}

A rigid block which is $5 \mathrm{~m}$ wide is covered on the left top of the vertical soil slope, ignoring deadweight. Concentrated load is applied vertically downward on the centre of block, the value of which is $200 \mathrm{kN}$. The right and bottom of slope are imposed constraints, as shown in Fig. 1. The finite element mesh is shown in Fig. 2, and there are a total of 700 units and 756 nodes. The cohesion and friction angle of slope soil are: $c=35 \mathrm{kPa}$ and $\varphi=31^{\circ}$, and the corresponding parameters of $\mathrm{P}-\mathrm{Z}$ model are shown in Tab. 1.

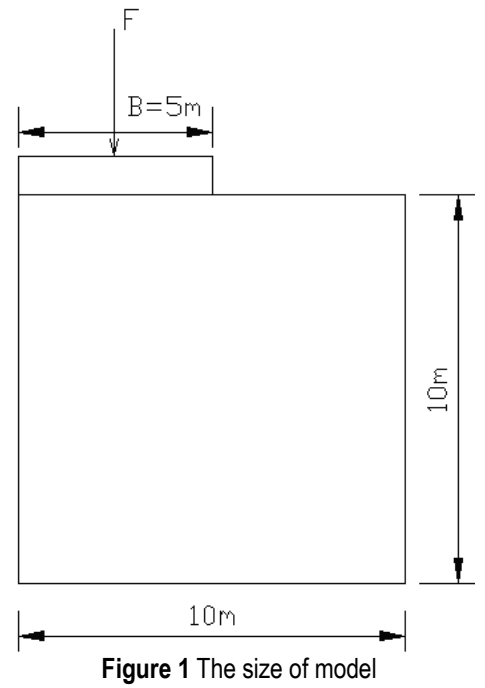

Table 1 Parameters of P-Z model
\begin{tabular}{|c|c|c|c|c|}
\hline Parameters & $M_{g}$ & $M_{f}$ & $\alpha_{g}$ & $\alpha_{f}$ \\
\hline Value & 1.42 & 0.64 & 0.45 & 0.45 \\
\hline Parameters & $\beta_{0}$ & $\beta_{1}$ & $H_{0}$ & $\gamma_{D M}$ \\
\hline Value & 4.2 & 0.2 & 380.0 & 1.5 \\
\hline Parameters & $H_{u 0}$ & $\gamma_{u}$ & $K_{\text {evo }}$ & $K_{\text {eso }}$ \\
\hline Value & 5320 & 3.0 & $81325 \mathrm{KPa}$ & $63980 \mathrm{KPa}$ \\
\hline
\end{tabular}

The angle between theoretical failure surface and the horizontal direction is $52.4^{\circ}$, and the safety factor is: $F=B c / F(\operatorname{ctan} \alpha+\tan \alpha)+\operatorname{ctan} \alpha \cdot \tan \theta=2.273$, and putting the calculation parameters in it can get $K=2.273$. Based on the given reduction parameters of $\mathrm{P}-\mathrm{Z}$ model, the static safety factor of model is 2.267 with the finite element strength reduction method. Comparing the calculated solution with the theoretical solution, the differences are only $4.4 \%$. The plastic zone distribution is shown in Fig. 3, and the diagram of displacement vector is shown in Fig. 4.

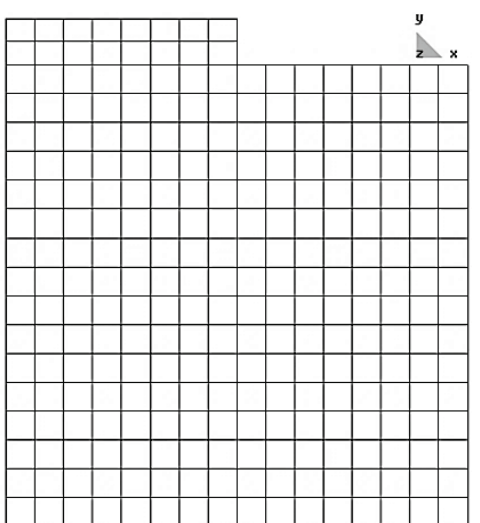

Figure 2 The finite element of mode

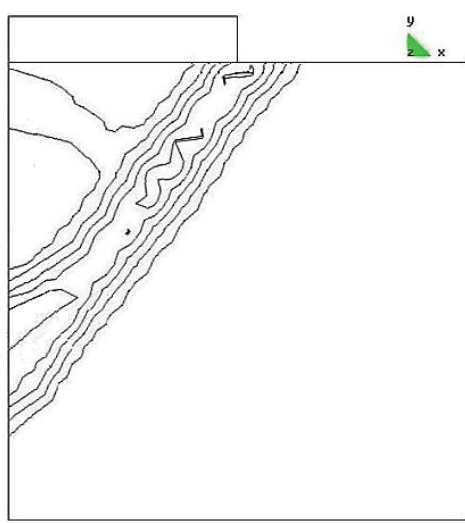

Figure 3 The plastic zone distribution

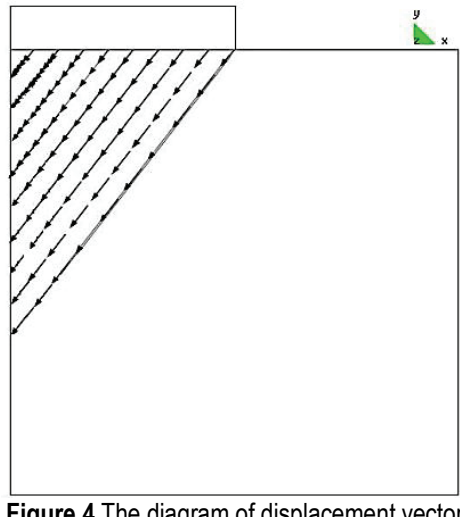

Figure 4 The diagram of displacement vecto

\section{THE METHOD OF STATIC AND DYNAMIC SLOPE STABILITY BASED ON P-Z MODEL \\ 3.1 Basic Principle}

The earthquake process is short, so it is assumed that the material parameters do not change in the dynamic stability analysis during the earthquake period on the basis of which a new method of dynamic stability analysis is proposed, and the basic ideas are: (1) Calculating a series of shear strength reduction factors of slope stability in static condition by nonlinear finite element mixing solution, then carrying out static and dynamic analyses with every reduction factor of material strength parameters, and the dynamic displacement time history and post-earthquake permanent displacement corresponding to every reduction factor are got. (2) Establishing the relation between post-earthquake permanent displacement of the feature point and shear strength reduction factor. (3) Taking the mutation of post- 
earthquake permanent displacement as the criteria of slope failure, the strength reduction factor corresponding to the displacement mutation of feature points is the dynamic stability safety factor of the slope.

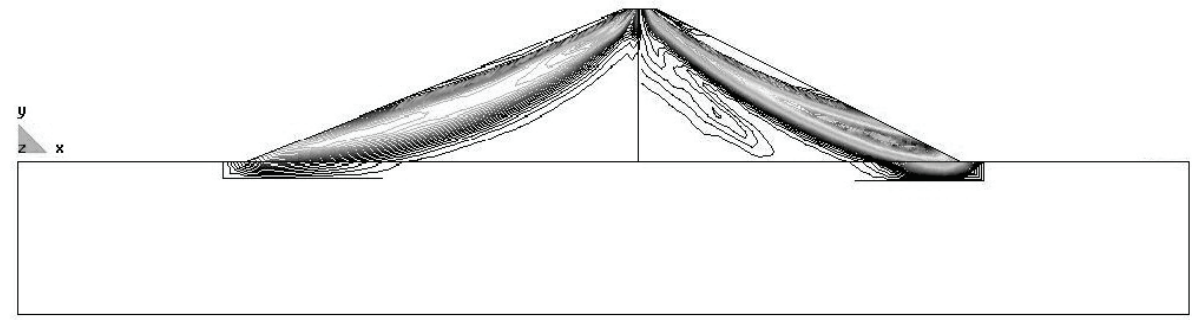

Figure 5 Distribution diagram of plastic zone

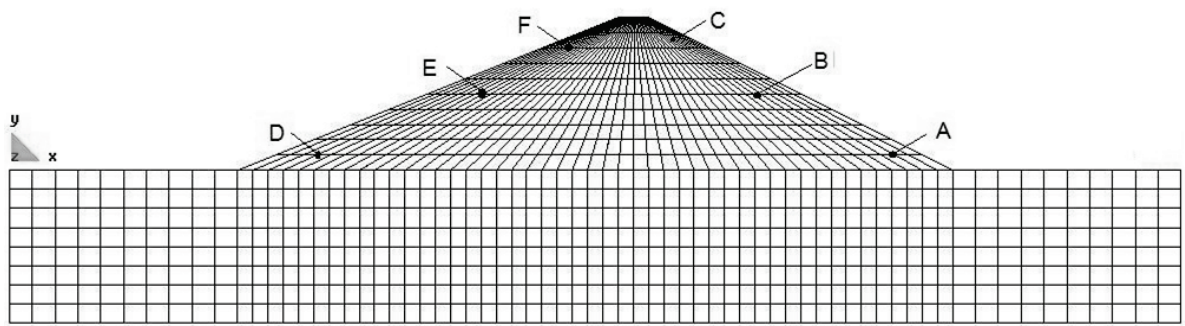

Figure 6 The finite element mesh and location of feature points

\subsection{Case 2}

The dam is $20 \mathrm{~m}$ height, and the upstream and downstream slope ratios are 1:2.5 and 1:2.0. The parameters are shown in Tab. 1.

The static safety factors of upstream and downstream slope are got by nonlinear finite element solution [20]. They are 1.818 and 1.515, and reduction factors of each iteration step are 1.0, 1.087, 1.190, 1.250, 1.316, 1.389, $1.471,1.515,1.667,1.724,1.818$. Distribution diagram of plastic zone is shown in Fig. 5.

Based on the idea of slope dynamic safety evaluation before, the static and dynamic analysis of slope is implemented by the selection of all finite element strength reduction factors, which are $1.0,1.087,1.190,1.250$, $1.316,1.389,1.471,1.515,1.667,1.724$. Three feature points in the plastic transfixion zone on each side of upstream slope and downstream slope are selected to calculate their dynamic displacement time history and post-earthquake permanent displacement, and the feature points are shown in Fig. 6. In the dynamic analysis, the truncation boundary of dam foundation is simulated as viscoelastic artificial boundary, and the seismic wave figures of acceleration, velocity and displacement time history in $X$ direction are shown in Fig. 7.

Results of relationship between post-earthquake permanent displacement of feature points and the reduction factors are shown in Tab. 2.
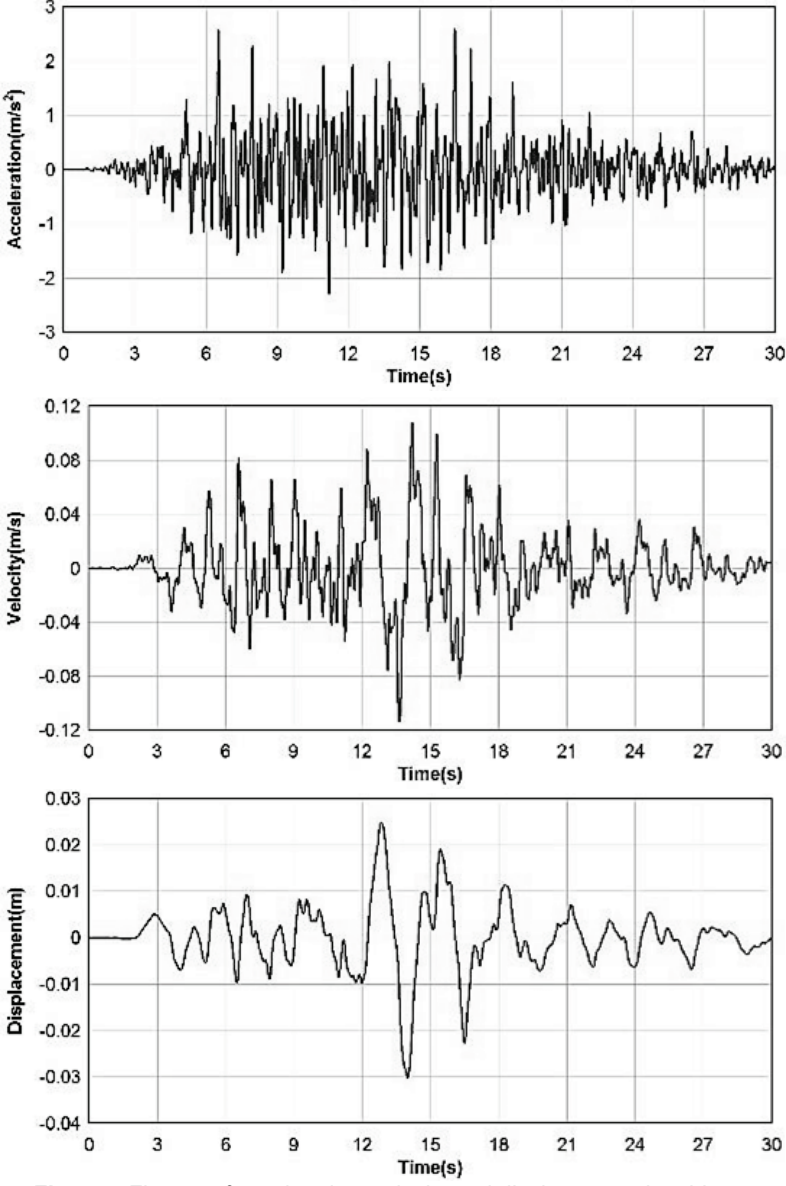

Figure 7 Figures of acceleration, velocity and displacement time history

Table 2 Relationship between post-earthquake permanent displacement and the reduction factors

\begin{tabular}{|c|c|c|c|c|c|c|c|c|c|}
\hline \multicolumn{2}{|l|}{ The reduction factors } & 1.0 & 1.19 & 1.25 & 1.316 & 1.389 & 1.471 & 1.667 & 1.724 \\
\hline \multirow{6}{*}{$\begin{array}{l}\text { The post-earthquake permanent } \\
\text { displacement of feature points } \\
\text { (m) }\end{array}$} & A & -0.080 & -0.086 & -0.088 & -0.091 & -0.095 & -0.102 & -0.110 & -0.122 \\
\hline & $\mathrm{B}$ & -0.161 & -0.190 & -0.202 & -0.210 & -0.226 & -2.217 & / & l \\
\hline & $\mathrm{C}$ & -0.153 & -0.181 & -0.195 & -0.198 & -0.200 & -0.214 & -0.221 & -0.230 \\
\hline & $\mathrm{D}$ & 0.071 & 0.080 & 0.086 & 0.090 & 0.092 & 0.095 & 0.109 & 0.138 \\
\hline & $E$ & 0.128 & 0.151 & 0.166 & 0.171 & 0.174 & 0.182 & 0.255 & 2.259 \\
\hline & $\mathrm{F}$ & 0.127 & 0.148 & 0.155 & 0.157 & 0.159 & 0.163 & 0.180 & 0.208 \\
\hline
\end{tabular}



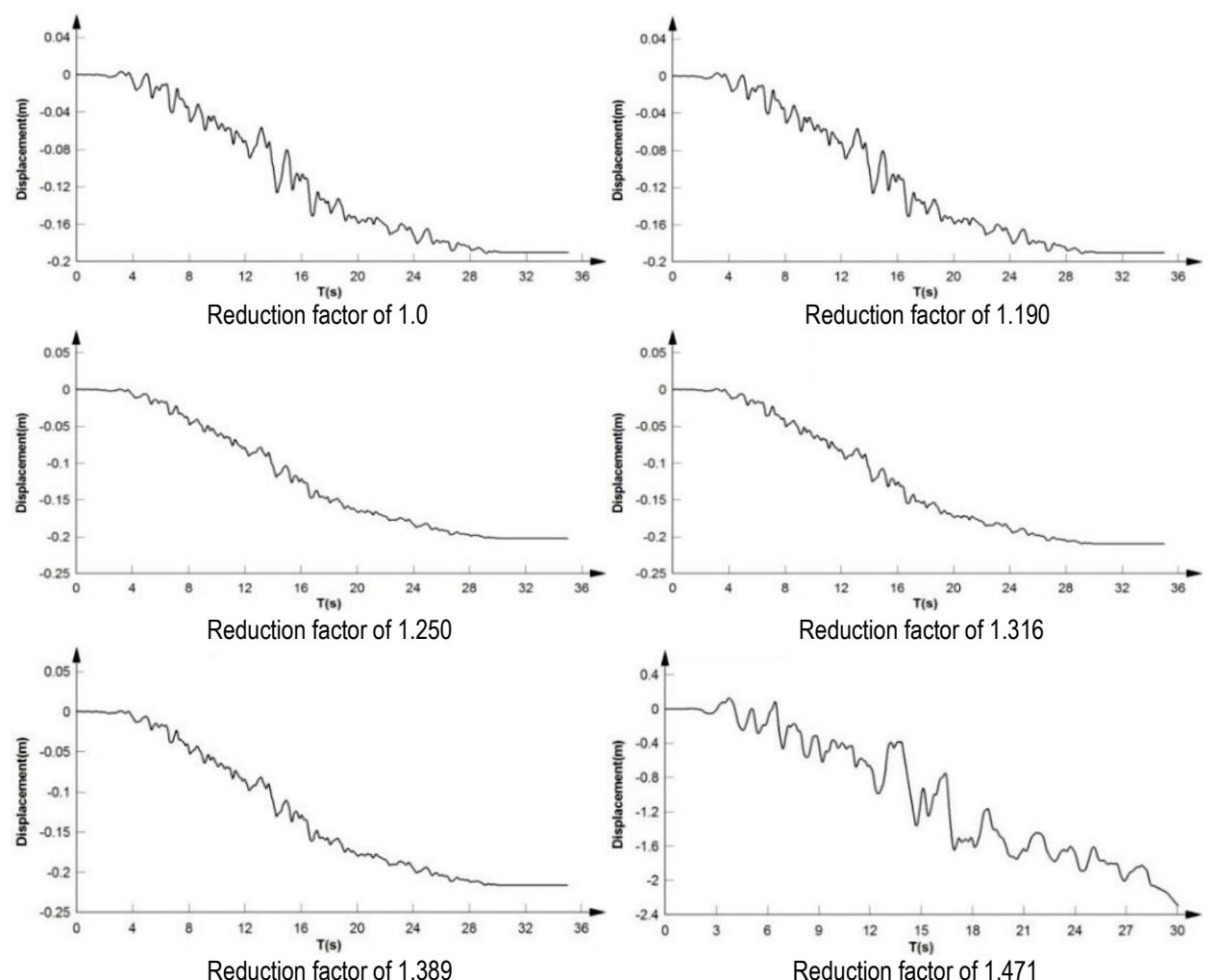

Figure 8 The dynamic displacement time history curves of feature points $B$
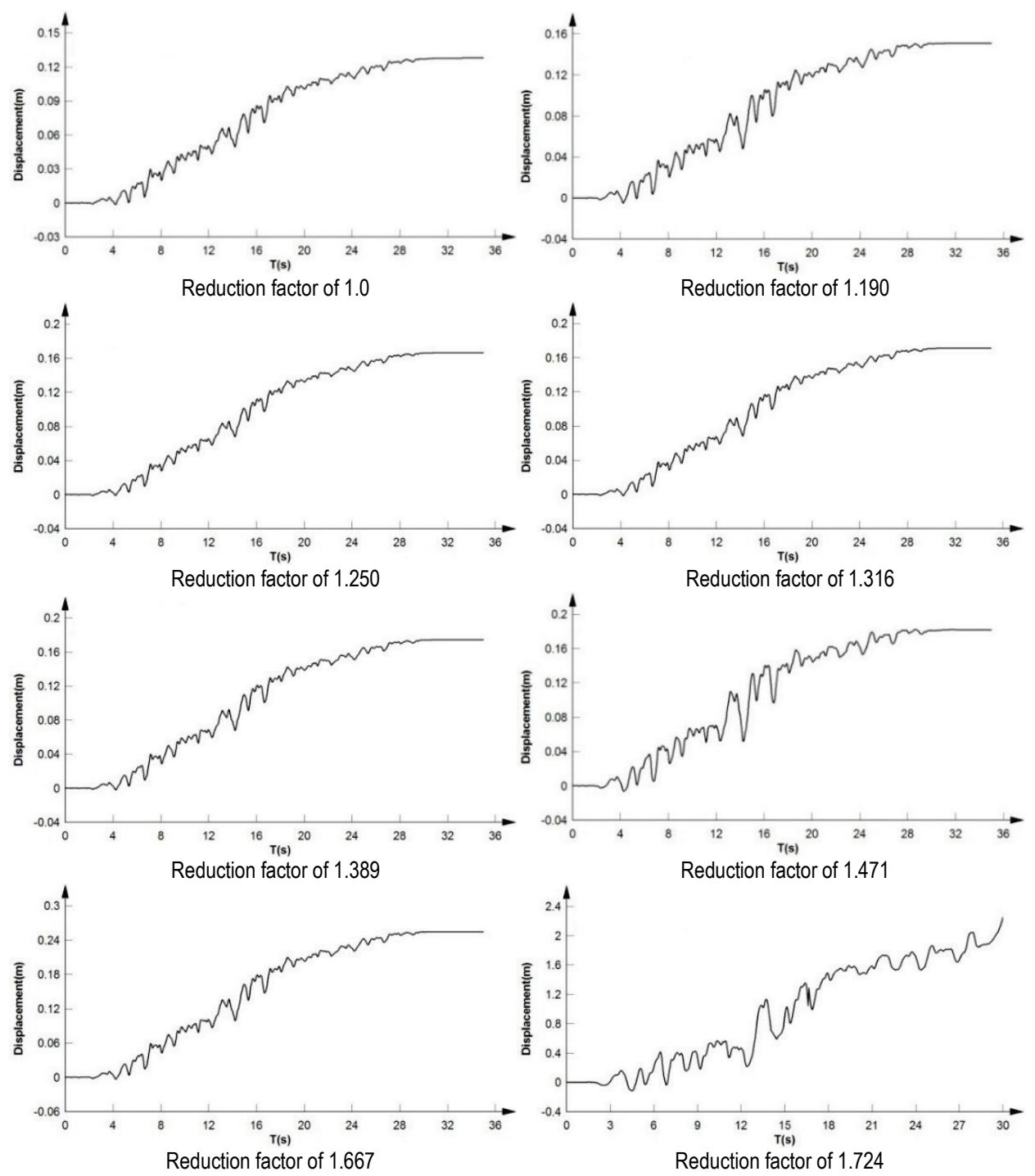

Figure 9 The dynamic displacement time history curves of feature points $\mathrm{E}$ 
In Tab. 2, post-earthquake permanent displacement of feature point increases with the increase of reduction factor. The permanent displacement of point $\mathrm{B}$ is bigger than that of points $\mathrm{A}$ and $\mathrm{C}$ on downstream slope, and mutates in the reduction factor of 1.471 . The displacement of $\mathrm{E}$ is bigger than the displacements of $\mathrm{D}$ and $\mathrm{F}$ on upstream slope, and mutates in the reduction factor of 1.724. The dynamic displacement time history curves of feature points $\mathrm{B}$ and $\mathrm{E}$ in each reduction factor are shown in Fig. 8 and Fig. 9

It is known from Fig. 8 and 9 that the displacement time history of each point is constantly accumulating and increasing for the adoption of the P-Z elastic-plastic model, and the post-earthquake permanent displacement of each point increases with the increasing of reduction factor. The curves between post-earthquake permanent displacement of feature points B, E and the safety factor which are established according to Tab. 2 and Fig. 8 and 9 are shown in Fig. 10.

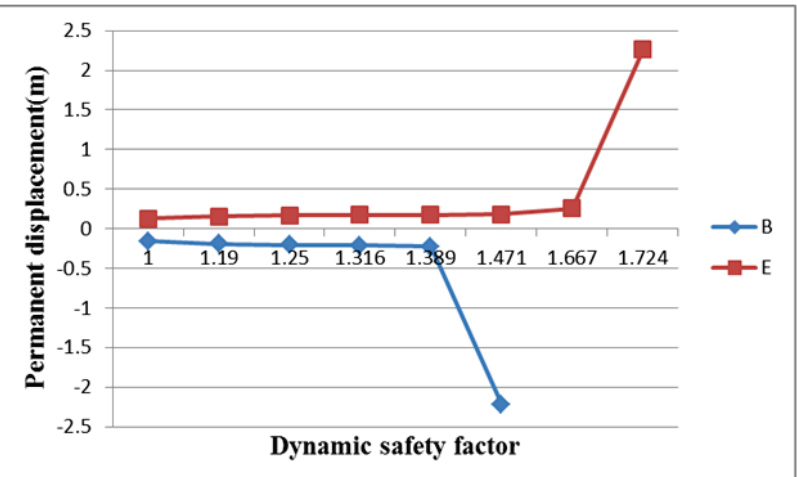

Figure 10 The curves between post-earthquake permanent displacement and the safety factor

It is known from figure 10 that the post-earthquake permanent displacement of point $\mathrm{B}$ mutates after the reduction factor of 1.389 under the dynamic load, which is the dynamic safety factor of the downstream slope. The post-earthquake permanent displacement of point $\mathrm{E}$ mutates after the reduction factor of 1.667 , which is the dynamic safety factor of the upstream slope. For permanent movement of points $\mathrm{A}, \mathrm{C}, \mathrm{D}$ and $\mathrm{F}$ in the postquake there are no immediate changes, but it can be considered that the dam locally loses stability.

\subsection{Comparisons of Several Analysis Methods of Slope Dynamic Stability}

Tab. 3 shows the dynamic safety factors of slope calculated by the proposed method, the pseudo-static method and the dynamic time-history method. Fig. 11 shows the dynamic safety factor curve by the time history method. Fig. 11 shows the dynamic safety factor curve of upstream and downstream slope.

Table 3 The dynamic safety factors calculated by different methods

\begin{tabular}{|c|c|c|c|}
\hline & $\begin{array}{c}\text { The proposed } \\
\text { method }\end{array}$ & $\begin{array}{c}\text { The pseudo- } \\
\text { static method }\end{array}$ & $\begin{array}{c}\text { The dynamic } \\
\text { time-history } \\
\text { method }\end{array}$ \\
\hline $\begin{array}{c}\text { Upstream } \\
\text { slope }\end{array}$ & 1.667 & 1.453 & 1.20 \\
\hline $\begin{array}{c}\text { Downstream } \\
\text { slope }\end{array}$ & 1.389 & 1.211 & 0.833 \\
\hline
\end{tabular}
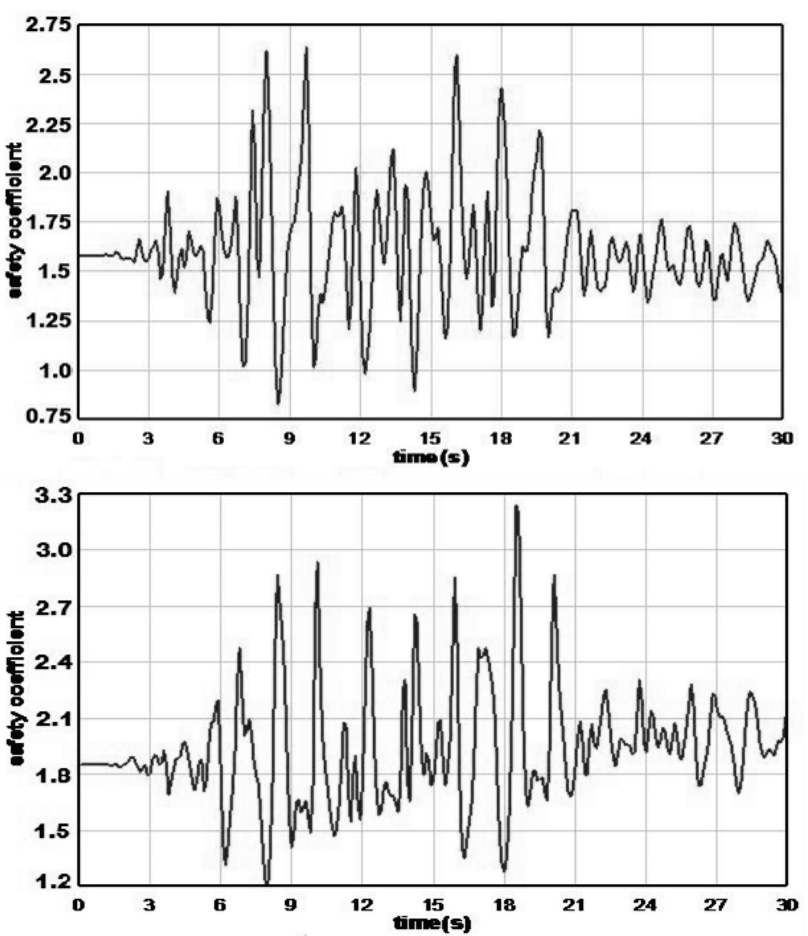

Figure 11 The dynamic safety factor curve of upstream and downstream slope

It is known from the table and figures above that the dynamic safety factor calculated by quasi-static method is less than that in the proposed model, and only it can judge the stability of slope in its entirety. The dynamic safety factor at each moment is obtained by time history analysis method, but there are no clear criteria about how to judge the stability of slope in the case the safety factor is less than 1 . Besides, the dynamic safety factor is calculated by the ratio of stabilizing force and sliding force at a moment, when the slope is not always in the limit equilibrium state, which is unreasonable. Comparing with traditional methods, the local slope instability can be judged and the change of permanent displacement and dynamic displacement can be got by the proposed method, which is more reasonable.

\section{CONCLUSION}

The dynamic stability of earth and rockfill dam slope is worrying and complicated, so the definition of dynamic safety factor, the constitutive model, the dynamic boundary and other factors need to be considered. The P$\mathrm{Z}$ constitutive model is introduced in the paper, and its strength reduction parameters are derived. Then a new method of dynamic stability analysis is put forward which judges the stability of slope by dynamic displacement time history and post-earthquake permanent displacement. By comparing the results of the proposed method to those of quasi-static method and dynamic safety factor time history method, it is known that the local slope instability can be judged and the change of permanent displacement and dynamic displacement can be got by the proposed method, which is more reasonable.

\section{Acknowledgements}

The author wishes to thank the National Natural Science Foundation of China for contract 51609087, Key 
project of scientific research in Colleges and Universities of Henan Province (15B570001, 17A570004), Collaborative Innovation Center of Water Resources Efficient Utilization and Protection Engineering, Henan Province, and Open Fund of Dike Safety and Disaster Prevention Engineering Technology Research Center of the Ministry of Water Resources, under which the present work was possible.

\section{REFERENCES}

[1] Liu, H., Fei, K. \& Gao, Y. (2003). Time history analysis method of slope seismic stability. Rock and Soil Mechanics, 24(4), 553-560. https://doi.org/10.16285/j.rsm.2003.04.015

[2] Li, Y., Gao, G. Y. \& Li, T. B. (2006). Analysis of earthquake response and stability evaluation for transverse slope at second tunnel portal. Chinese Journal of Underground Space and Engineering, 2(5), 738-743. https://doi.org/10.3969/j.issn.1673-0836.2006.05.009

[3] Ma, F. (2005). Study on the seismic stability of slope based on time history analysis method and finite element method. DaLian: Dalian University of Technology. https://doi.org/10.7666/d.y715549

[4] Zhang, B. Y., Zhang, J. H. \& Sun, G. L. (2015) Deformation and shear strength of rockfill materials composed of soft siltstones subjected to stress, cyclical drying/wetting and temperature variations. Engineering Geology, 190, 87-97. https://doi.org/10.1016/j.enggeo.2015.03.006

[5] Laloui, L., Ferrari, A., Li, C. \& Eichenberger, J. (2016). Hydro-mechanical analysis of volcanic ash slopes during rainfall. Geotechnique, 66(3), 220-231. https://doi.org/10.1680/jgeot.15.LM.001

[6] Sun, C., Li, C., Zheng, H. \& Sun, G. (2014). A strength reduction finite element method based on softening properties analysis for 3D slope. Rock and Soil Mechanics, 35(s1), 67-70. https://doi.org/ 10.16285/j.rsm.2014.s1.027

[7] Chen, S., Li, G. Y. \& Fu, Z. (2013). Safety criteria and limit resistance capacity of high earth-rock dams subjected to earthquakes. Chinese Journal of Geotechnical Engineering, 35(1), 59-65

[8] Yang, X. \& Chi, S. (2013). Upper bound method for seismic stability limit analysis of earth-rock dams. Rock and Soil Mechanics, 34(3), 721-726. https://doi.org/10.16285/j.rsm.2013.03.030

[9] Liu, X., Tu, Y., Zhong, Z. \& Liu, Y. (2016). Slope's failure criterion based on energy catastrophe in shear strength reduction method. Journal of Central South University (Science and Technology), 47(6), 2065-2072. https://doi.org/10.11817/j.issn.1672-7207.2016.06.034

[10] Zhou, Y. F., Deng, J. H., Cui, Y., Zheng, H. \& Chen, T. (2014). Instability criterion of three-dimensional slope based on strength reduction method. Rock and Soil Mechanics, 35(5), 1432-1437. https://doi.org/10.16285/j.rsm.2014.05.029

[11] Zou, Y., Guo, M., Wang, S. \& Ge, X. (2017). Dynamic stability analysis of three dimensional slope under seismic load. Chinese Journal of Rock Mechanics and Engineering, 36(3), 1-11. https://doi.org/10.13722/j.cnki.jrme.2016.1241

[12] Zienkiewicz, O. C. \& Mroz, Z. (1984). Generalized plasticity formulation and applications to Geomechanics. Mechanics of Engineering Materials, 44(3), 655-679.

[13] Pastor, M., Zienkiewicz, O. C. \& Leung, K. H. (1985). Simple model for transient soil loading in earthquake analysis (II): Non-associative models for sands. International Journal for Numerical and Analytical Methods in Geomechanics, 9, 477-498. https://doi.org/10.1002/nag.1610090506
[14] Pastor, M. \& Zienkiewicz, O. C. (1986). A generalized plasticity hierarchical model for sand under monotonic and cyclic loading. London: Jackson and Son, 131-150.

[15] Pastor, M., Zienkiewicz, O. C. \& Chan, H. C. (1990). Generalized plasticity and the modeling of soil behaviour. International Journal for Numerical and Analytical Methods in Geomechanics, 14(1), 151-160. https://doi.org/10.1002/nag.1610140302

[16] Zhang, H., Han, L., Zhang, X. \& Xu, C. (2014). The P-Z model for core materials of earth-rockfill dam. International journal of earth sciences and engineering, 7(2), 668-774.

[17] Zhang, H., Zhang, X., Li, X. \& Xu, C. (2016). Study on wetting deformation of earth-rockfill dam based on The P-Z model. International Journal of Earth Sciences and Engineering, 7(2), 697-703.

[18] Zhang, H. (2010). Research on method of static-dynamic stability analysis for slope of high earth and rockfill dam basing on the P-Z model. NanJing: Hohai University.

[19] Zhang, H., Li, T., Gong, B. \& Niu, Z. (2009). Introduction and shaking table test verification of the $\mathrm{P}-\mathrm{Z}$ model for sand soil. Journal of Hydroelectric Engineering, 28(5), 182-186.

[20] Zhou, G. (2010). Finite element iteration method for safety factor of slope stability based on strength reduction method. Advances in Science and Technology of Water Resources, 30(3), 58-61. https://doi.org/10.3880/j.issn.1006-7647.2010.03.015

\section{Contact information}

\section{Hongyang ZHANG}

North China University of Water Resources and Electric Power,

Collaborative Innovation Center of Water Resources Efficient Utilization and

Protection Engineering of Henan Province, Zhengzhou 450046, China

Email: zhyncwu@163.com

Shuai LI

North China University of Water Resources and Electric Power,

Zhengzhou 450046, China

Email: 779884149@qq.com

\section{Xianqi ZHANG}

Corresponding author

North China University of Water Resources and Electric Power,

Zhengzhou 450046, China

Email: zxqi@163.com

\section{Liwei HAN}

North China University of Water Resources and Electric Power,

Zhengzhou 450046, China

Email: Hanliwei13@163.com

\section{Zelin DING}

North China University of Water Resources and Electric Power,

Zhengzhou 450046, China

Email: dingzelin@126.com

\section{Cundong XU}

North China University of Water Resources and Electric Power

Zhengzhou 450046, China

Email: xcundong@126.com 